\title{
Stock Lagoa de Dentro, Domínio Macururé, Sistema Orogênico Sergipano: Geologia, Petrografia e Geoquímica
}

\author{
Lagoa de Dentro Stock, Macururé Domain, Sergipano Orogenic System: Geology, Petrography \\ and Geochemistry
}

\author{
F. S. Pereira ${ }^{1 *}$; J. A. Conceição ${ }^{1,2}$; M. L. S. Rosa ${ }^{1,3} ;$ H. Conceição ${ }^{1,3}$ \\ ${ }^{1}$ Bolsista de Iniciação Científica do Conselho Nacional de Desenvolvimento Científico e Tecnológico (CNPq), \\ Universidade Federal de Sergipe, 49100-000, São Cristóvão, Sergipe, Brasil \\ ${ }^{2}$ Bolsista de Doutorado do Conselho Nacional de Desenvolvimento Científico e Tecnológico (CNPq), Pós-Graduação \\ em Geologia, Universidade Federal da Bahia, 40170-020, Salvador, Bahia, Brasil \\ ${ }^{3}$ Programa de Pós-Graduação em Geociências e Análise de Bacias, Complexo Laboratorial Multiusuários da \\ Univerdidade Federal de Sergipe, Galpão das Geociências, 49100-000, São Cristóvão, Sergipe, Brasil \\ *fabio.santos.pereira@hotmail.com \\ (Recebido em 12 de dezembro de 2016; aceito em 11 de janeiro de 2017)
}

\begin{abstract}
O Domínio Macururé aloja uma importante granitogênese neoproterozoica, que registra os principais eventos ocorridos durante a evolução do Sistema Orogênico Sergipano. O Stock Lagoa de Dentro (SLD) é um dos representantes do magmatismo granítico leucocrático identificado no Domínio Macururé, cuja gênese é, em parte, atribuída à fusão dos seus metassedimentos. O SLD possui $13 \mathrm{~km}^{2}$ de área e encontrase intrusivo nos metassedimentos psamo-pelíticos dos municípios de Gracho Cardoso e Cumbe. Suas rochas têm cor cinza a rosa, granulação média, são hololeucocráticas e equigranulares. Os tipos petrográficos que compõem o stock são Muscovita Álcali-Feldspato Granito, Muscovita Monzogranito e Monzogranito. Os dados geoquímicos revelam que as rochas do SLD são fortemente fracionadas $\left(\mathrm{SiO}_{2}>67 \%\right)$, peraluminosas $(1,07<\mathrm{A} / \mathrm{CNK}<1,32)$, potássicas e apresentam afinidade com as suítes Cálcio-Alcalinas de Alto $\mathrm{K}$ e Shoshonítica. Os conteúdos de elementos traços posicionam as rochas estudadas no campo dos granitos sin-colisionais, com uma assinatura de magmas gerados em ambiente de arco vulcânico.

Palavras-chave: Sistema Orogênico Sergipano, Stock Lagoa de Dentro, Granito
\end{abstract}

The Macururé Domain hosts an important neoproterozoic granitogenesis, which records the main events that occurred during the evolution of the Sergipano Orogenic System. The Lagoa de Dentro Stock (SLD) is one of the representatives of the granitic leucocratic magmatism identified in the Macurure Domain, whose genesis is partly attributed to the fusion of its metasediments. The SLD has $13 \mathrm{~km}^{2}$ of area and is intrusive in the psamo-pelitic metasediments of the counties of Gracho Cardoso and Cumbe. Its rocks are gray to pink, medium grained, hololeucocratic and equigranular. The petrographic types that make up the stock are Muscovite Alkali-Feldspar Granite, Muscovite Monzogranite and Monzogranite. The geochemical data show that SLD rocks are strongly fractionated $\left(\mathrm{SiO}_{2}>67 \%\right)$, peraluminous $(1.07<\mathrm{A} / \mathrm{CNK}<1.32)$, potassic and present affinity with the High-K Calc-Alkaline and Shoshonite suites. The contents of trace elements position the studied rocks in the field of the collisional granites, with a signature of magmas generated in a volcanic arc environment.

Keywords: Sergipano Orogenic System, Lagoa de Dentro Stock, Granite

\section{INTRODUÇÃO}

O Sistema Orogênico Sergipano (SOS) [1] representa uma reunião de terrenos estruturada em formato triangular e direção WNW-ESE, situada no setor extremo sul da Província Borborema, na região nordeste do Brasil. O SOS já foi interpretado como um geossinclinal [2, 3, 4], como uma colagem de domínios aloctónes [5] e, mais recentemente, como um orógeno resultante da inversão de uma margem passiva continental desenvolvida na parte norte do Cráton do São Francisco [6,7].

Apesar da divergência de opiniões quanto a sua evolução, na atual compartimentação do SOS [5] são reconhecidos seis domínios geológicos, nomeados, de norte para sul: Canindé, Poço 
Redondo, Marancó, Macururé, Vaza Barris e Estância, que são delimitados por zonas de cisalhamento contracionais de alto ângulo.

No contexo do SOS, o Domínio Macururé (Figura 1A) representa uma cunha turbidítica mesoproterozoica com mais de $13 \mathrm{~km}$ de espessura [7], composta principalmente por pelitos, mármores e quartzitos subordinados [5], que foi submetida localmente a condições metamórficas que atingem a Fácies Anfibolito [1] e por uma suíte granitos colisionais brasilianos e alguns corpos máficos de idade indeterminada (Figura 1B).

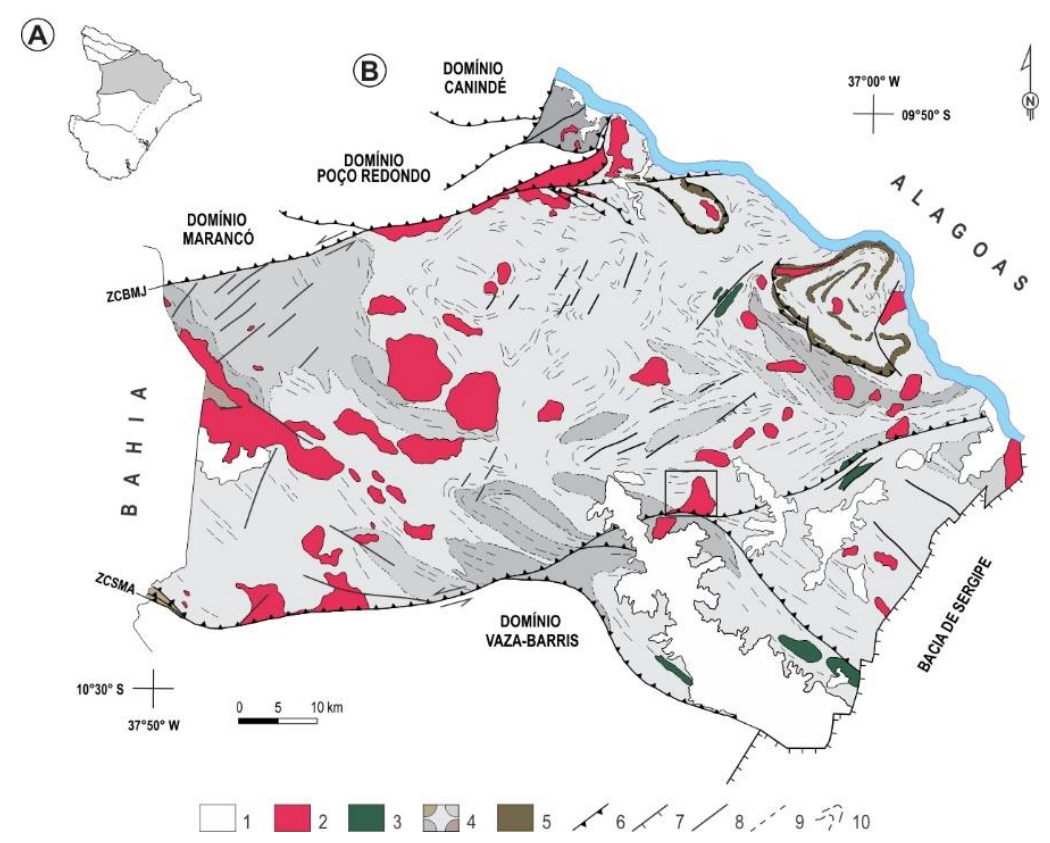

Figura 1: (A) Contorno do Estado de Sergipe, com destaque em cinza para o Domínio Macururé. (B) Esboço geológico mostrando a distribuição dos granitos do Domíno Macururé após Souza \& Santos (1997) [13]. Os seus contatos com os domínios adjacentes são feitos pelas zonas de cisalhamento de São Miguel do Aleixo (ZCSMA) e Belo Monte-Jeremoabo (ZCBMJ). A região em destaque, delimitada pelo retângulo preto, corresponde à área de estudo. Coberturas terrígenas (1), granitoides brasilianos (2), corpos máficos (3), metassedimentos (4), quartzitos (5), zona de cisalhamento contracional (6), falha extensional (7), contato definido (8), contato gradacional (9), foliação regional (10).

Estudos recentes nos granitos $[8,9,10,11,12]$ revelam a variedade de tipos petrográficos, comprovam a predominância da assinatura cálcio-alcalina desse plutonismo e fornecem um panorama geral acerca dos processos responsáveis pela geração dos seus magmas, contribuindo no entendimento do significado desses corpos no cenário geodinâmico regional.

Assim, com vistas a suprir parte da carência de trabalhos em escala de detalhe nas intrusões graníticas do SOS, esta pesquisa apresenta e discute dados geológicos, petrográficos e geoquímicos do Stock Lagoa de Dentro (SLD), que é um dos representantes do magmatismo granítico leucocrático do Domínio Macururé e localiza-se entre as cidades de Gracho Cardoso e Cumbe.

\section{MATERIAL E MÉTODOS}

A etapa inicial da pesquisa fundamentou-se na obtenção de dados sobre a geologia da região estudada e na confecção de um mapa geológico, a partir da interpretação de 18 fotografias aéreas em escala de 1:25.000.

Em seguida, foram realizadas missões de campo para coleta de amostras e demarcação cartográfica do corpo granítico. Durante as atividades de campo, foram visitados e descritos dez afloramentos, cujas coordenadas UTM foram verificadas por meio de um GPS, empregando-se o datum SAD69. As rochas identificadas tiveram caracterizados seus aspectos texturais e mineralógicos, e as medidas das estruturas dessas rochas foram realizadas com uma bússola 
Brunton. Foram coletadas quatro amostras representativas do plúton e uma das suas encaixantes metassedimentares, as quais foram preparadas para confecção de lâminas delgadas e análises químicas.

Os estudos petrográficos foram executados nas dependências do Laboratório de Microscopia e Lupas do Departamento de Geologia da UFS (DGEOL-UFS), com o auxílio de microscópio petrográfico trinocular da marca Opton (TNP-09T). A análise modal foi realizada por meio de estimativa volumétrica visual de 40 campos não superpostos de cada lâmina, com a objetiva de $4 \mathrm{x}$. A nomenclatura das rochas seguiu a terminologia recomendada pela Subcomissão sobre Sistemática de Rochas Ígneas da International Union of Geological Sciences [14].

$\mathrm{O}$ estudo geoquímico foi realizado a partir das quatro amostras do SLD. Três das amostras foram analisadas para elementos maiores, menores e traços na Acme Analytical Laboratories, em Vancouver, por ICP-OES e ICP-MS. A amostra restante foi analisada por FRX apenas para elementos maiores, nas dependências do Condomínio Laboratorial Multiusuários das Geociências da UFS (CLGeo-UFS). Para tratamento e análise dos dados químicos, utilizou-se o software Geochemical Data Toolkit for Windows (GCDkit) versão 3.00 [15].

\section{RESULTADOS E DISCUSSÃO}

\subsection{Geologia Local}

O SLD é um stock localizado nos municípios de Gracho Cardoso e Cumbe, na porção centronorte do Estado de Sergipe. Este corpo ocupa área de $13 \mathrm{~km}^{2}$ e possui geometria aproximadamente elíptica, com eixo maior orientado segundo a direção N-S (Figura 2).

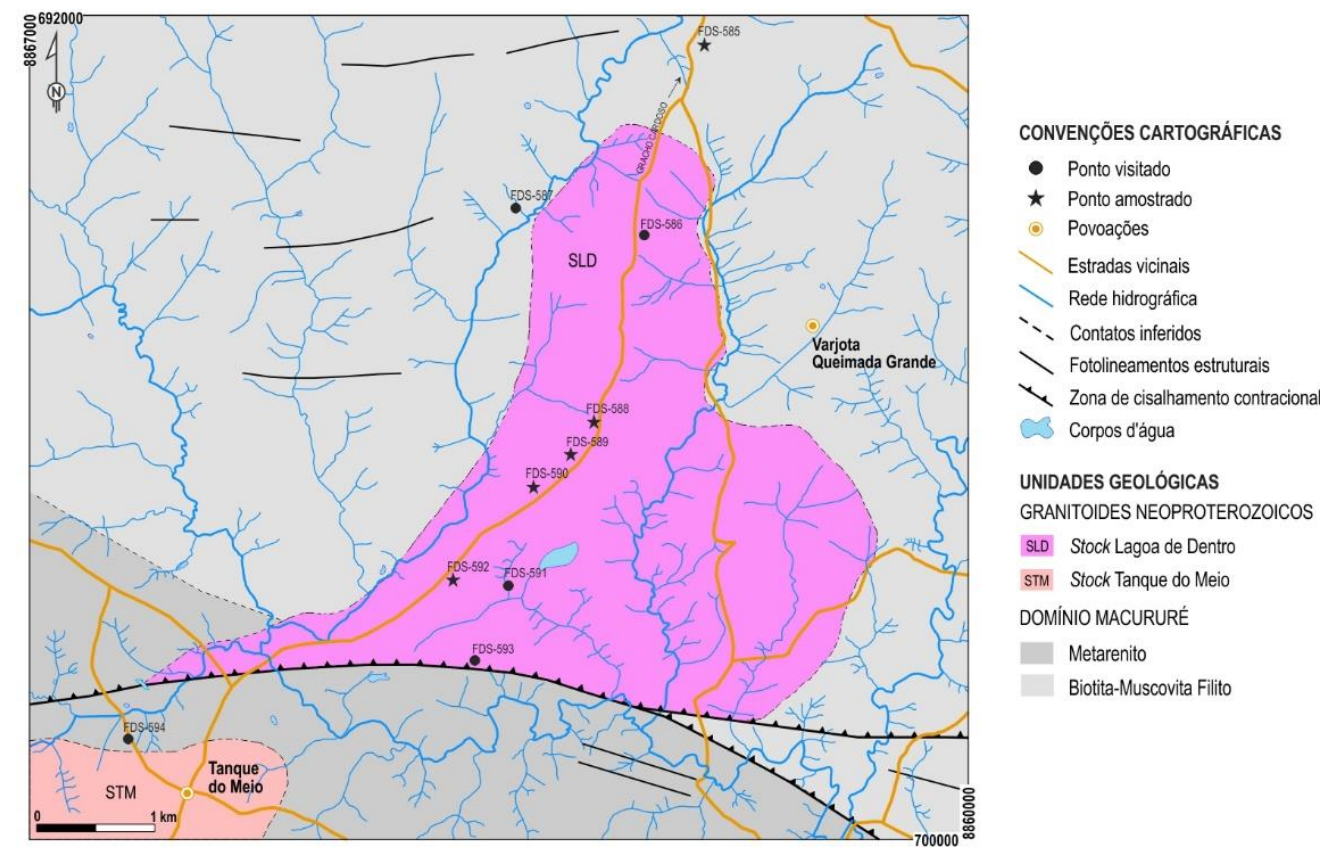

Figura 2: Mapa geológico simplificado da área de estudo.

Os afloramentos do SLD são escassos e localizam-se, sobretudo, ao longo da estrada que liga a sede municipal de Gracho Cardoso ao Povoado de Tanque do Meio, em Cumbe. As principais formas de afloramento são blocos e lajedos com dezenas a centenas de metros que se sobressaem na superfície em relação a planície generalizada da região.

Em campo, as rochas do SLD exibem grande homogeneidade composicional e textural, sendo constituídas por granitos à muscovita e biotita, de coloração cinza a rósea, com textura equigranular e granulação média (Figura 3A). Esses granitos são essencialmente isotrópicos, embora localmente possa ser observada uma incipiente foliação marcada pela orientação magmática dos cristais de micas. 
O SLD encontra-se intrusivo nos metassedimentos do Domínio Macururé. Os biotitamuscovita filitos representam as rochas de maior expressão na região estudada. Estas apresentam coloração amarronzada, textura equigranular, granulação fina a muito fina, brilho lustroso e tato untuoso (Figura 3B). O baixo grau metamórfico a que essas rochas foram submetidas é evidenciado pela preservação do acamamento sedimentar, marcado por intercalações rítmicas de níveis milimétricos de argilitos e siltitos. A verticalização do ângulo de mergulho destas rochas é observada à medida que se aproxima do stock, evidenciando o caráter intrusivo do corpo granítico.
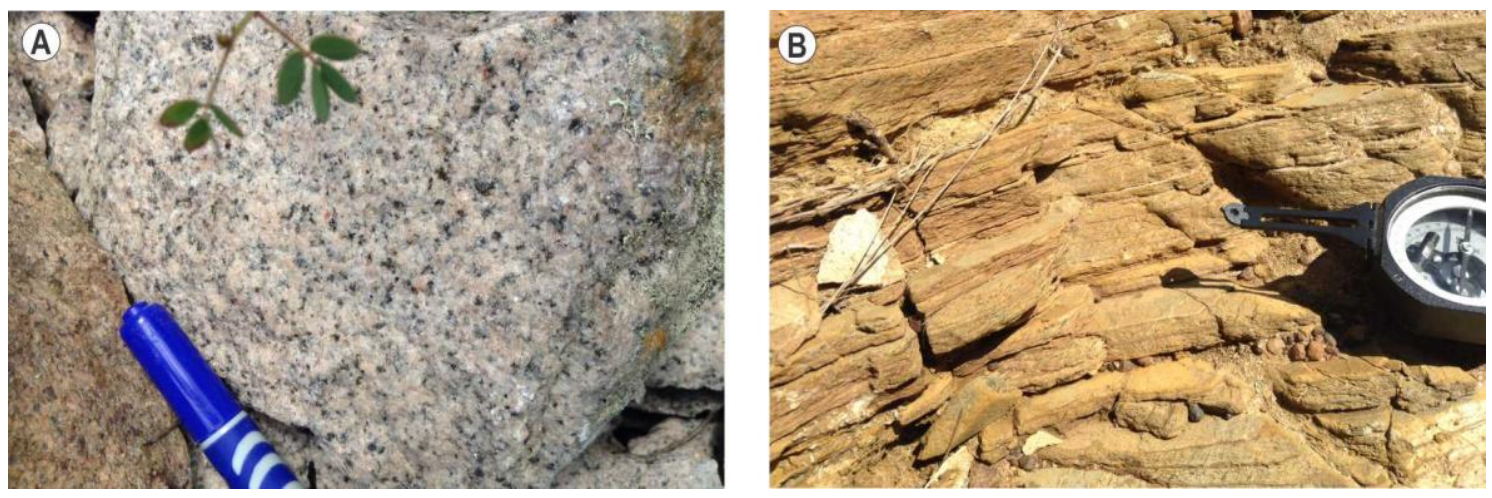

Figura 3: (A) Textura representativa da Fácies Muscovita Monzogranito, constituída por rochas de coloração rosada, com granulação média e textura equigranular. (B) Aspecto geral dos filitos do Domínio Macururé, encaixantes do SLD na porção norte da área de estudo.

Na porção sul da área, as encaixantes metamórficas passam a ser metarenitos. Quando não alteradas, essas rochas são compactas e exibem acamamento reliquiar preservado. Apresentam cor cinza-escura a bege, textura equigranular e granulação fina.

As atitudes das foliações obtidas nos metassedimentos ( $\left.N 055^{\circ} / 42^{\circ} \mathrm{NW}\right)$ são concordantes com a foliação magmática identificada do SLD (N061\%/48 $\mathrm{NW}$ ), sugerindo que a colocação desses granitos ocorreu em estágio sincrônico ao evento tectônico que estruturou a região.

\subsection{Petrografia}

As rochas do SLD apresentam estrutura isotrópica, granulação média e textura equigranular allotriomórfica (Figura 4). A mineralogia essencial das rochas que compõem o SLD é constituída por quartzo, albita e microclina, enquanto muscovita, biotita e epídoto geralmente ocorrem como minerais varietais. Apatita, zircão, rútilo, titanita e minerais opacos são os acessórios. Os minerais secundários usuais são clorita, calcita, sericita, epídoto e titanita.

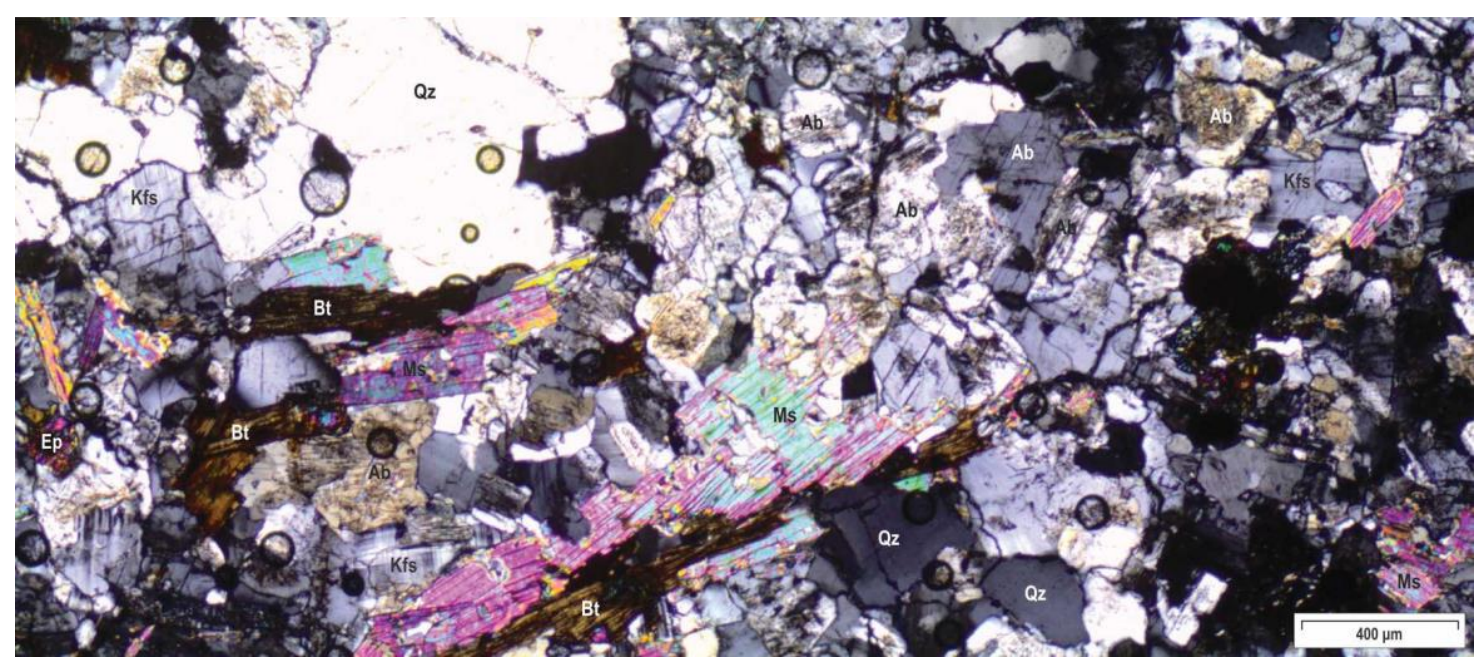

Figura 4: Textura representativa dos granitos do Stock Lagoa de Dentro. Quartzo (Qz), microclina $(K f s)$, albita $(A b)$, muscovita $(M s)$, biotita (Bt), epídoto (Ep). 
Os dados modais para as rochas do SLD são apresentados na Tabela 1. De acordo com a classificação proposta pela IUGS [14], essas rochas são hololeucocráticas e possuem composição monzogranítica a álcali-feldspato granítica (Figura 5). Os tipos petrográficos identificados foram: Muscovita Álcali-Feldspato Granito, Muscovita Monzogranito e Monzogranito.

Tabela 1: Análise modal das rochas do SLD. Muscovita Álcali-Feldspato Granito (MAFG), Muscovita Monzogranito (MMG), Monzogranito (MG).

\begin{tabular}{lrrrr}
\hline $\begin{array}{l}\text { Amostras } \\
\text { Fácies }\end{array}$ & $\begin{array}{c}\text { FDS-588 } \\
\text { MAFG }\end{array}$ & $\begin{array}{c}\text { FDS-589 } \\
\text { MMG }\end{array}$ & $\begin{array}{c}\text { FDS-590 } \\
\text { MAFG }\end{array}$ & $\begin{array}{c}\text { FDS-592 } \\
\text { MG }\end{array}$ \\
\hline Quartzo & 39,54 & 34,35 & 36,26 & 40,32 \\
Albita & 29,83 & 28,17 & 31,03 & 27,06 \\
$(\%$ An) & $(4)$ & $(7)$ & $(2)$ & $(6)$ \\
Microclina & 19,06 & 21,19 & 21,20 & 27,00 \\
Muscovita & 8,37 & 7,94 & 8,08 & 4,35 \\
Biotita & 1,26 & 4,92 & 1,71 & 0,57 \\
Epídoto & 0,83 & 1,58 & 0,17 & 0,70 \\
Apatita & 0,20 & 0,15 & $<0,10$ & $<0,10$ \\
Zircão & $<0,10$ & $<0,10$ & $<0,10$ & $<0,10$ \\
Rútilo & - & - & $<0,10$ & - \\
Titanita & - & - & - & $<0,10$ \\
Calcita & - & - & 0,97 & $<0,10$ \\
Sericita & $<0,10$ & $<0,10$ & $<0,10$ & $<0,10$ \\
Minerais opacos & 0,91 & 1,70 & 0,58 & $<0,10$ \\
\hline
\end{tabular}

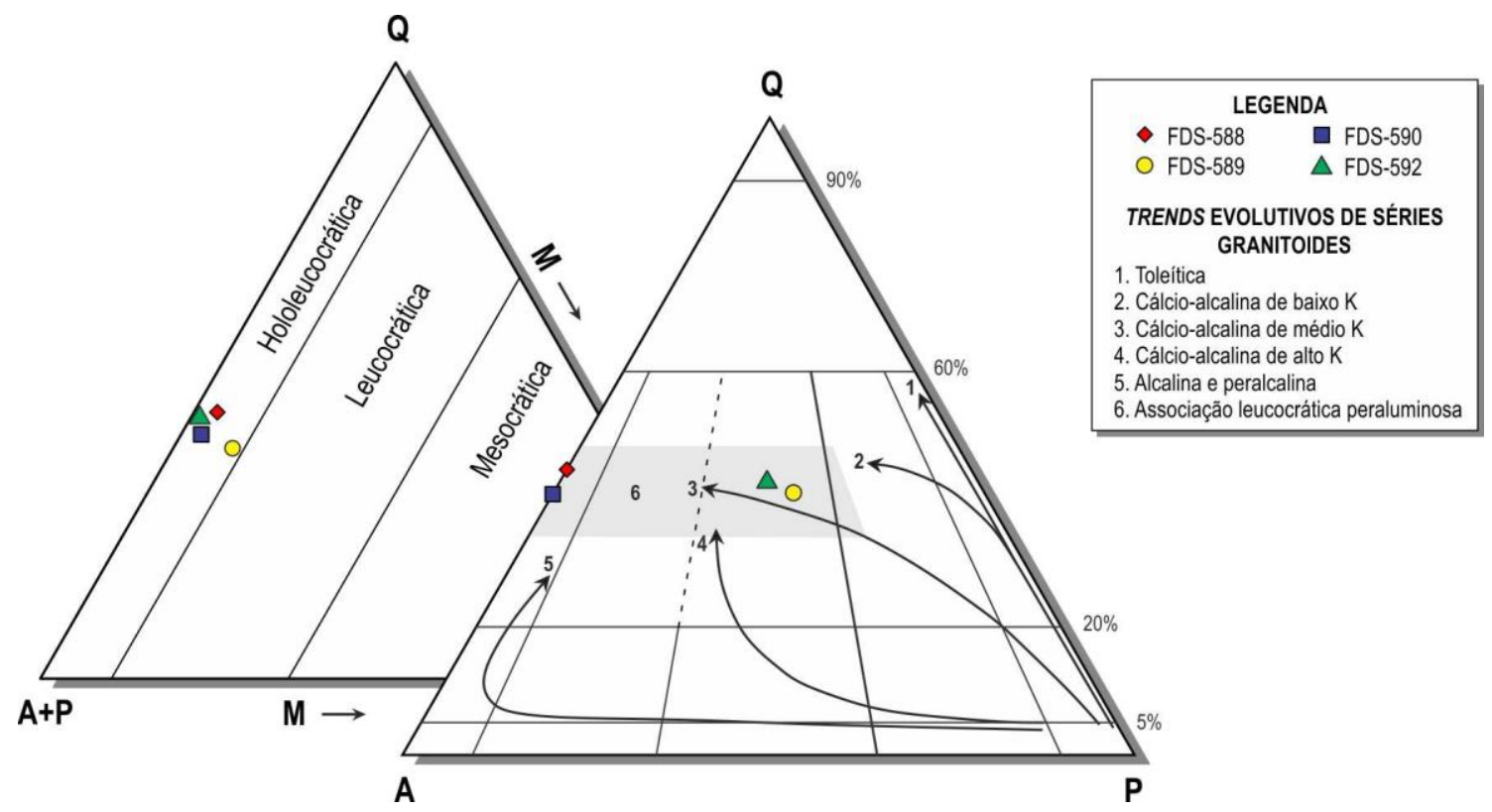

Figura 5: Diagramas $Q-A-P$ e $Q-(A+P)-M$ [16] para classificação de rochas ígneas plutônicas aplicado às rochas do SLD. Os itens 1 a 6 correspondem aos trends evolutivos de séries granitoides [17].

O quartzo ocorre como cristais anédricos, que estabelecem contatos curvos com os demais minerais da rocha. Comumente estes cristais exibem abundantes inclusões fluidas, apresentam extinção ondulante de intensidade fraca a moderada e incluem cristais de albita e microclina.

A albita $\left(\mathrm{An}_{2-7}\right)$ é anédrica a subédrica. A maioria dos cristais mostra-se geminada segundo as leis Albita e Albita-Carlsbad, cujos planos de composição apresentam traçados irregulares e descontínuos. Os contatos são curvos e reentrantes com a maior parte dos minerais da rocha e difusos com microclina. As principais inclusões são cristais de microclina, muscovita, apatita e epídoto. Muitos cristais exibem extinção ondulante concêntrica difusa de intensidade fraca a moderada. Alteração é comum em grande parte dos cristais, nos quais o centro geralmente ocorre 
alterado para sericita, epídoto ou carbonato e com aspecto de sujo, contrastando com as bordas, pouco ou não alteradas.

A microclina mostra-se anédrica e com geminação bem desenvolvida segundo as leis AlbitaPericlina, as quais apresentam indivíduos geminados limitados por planos de composição bem estruturados por toda a extensão dos cristais. Os contatos são difusos com albita e curvos com as outras fases minerais presentes na rocha. O seu aspecto é geralmente límpido e as inclusões mais comuns são cristais de albita e muscovita. Frequentemente exibem fraca extinção ondulante.

A muscovita apresenta-se anédrica a subédrica e, comumente, exibe kink bands (Figura 6A). Os contatos são curvos e reentrantes com a maior parte dos minerais adjacentes e retos com albita e clorita. Ocorrem como cristais individuais distribuídos de forma aleatória pela rocha ou em agregados irregulares associados com biotita, clorita e epídoto. Inclui cristais de quartzo, albita, apatita e epídoto.

A biotita ocorre euédrica a anédrica, exibe cor marrom e pleocroísmo variando de castanhoclaro a castanho-escuro. Os contatos são curvos com a maioria dos minerais da lâmina, sendo estes retos quando em limite com outros cristais de micas. Os cristais dispõem-se sob a forma de agregados irregulares, associados com muscovita e epídoto. Geralmente apresentam inclusões de minerais opacos, que também ocorrem preenchendo os seus planos de clivagem.

O epídoto possui cor verde-pálida e discreto pleocroísmo em tons de verde-claro a incolor. Duas variedades texturais são observadas: epídoto primário e secundário. O primeiro grupo reúne cristais euédricos e subédricos, que ocorrem em associação com biotita e muscovita, formando aglomerados em porções restritas da rocha (Figura 6B). Nestes cristais, são evidentes texturas de reabsorção, responsáveis pela geração de embaiamentos e corrosão parcial de faces cristalinas. Os contatos com os outros minerais são retos ou reentrantes. Por outro lado, os cristais de epídoto secundário são anédricos, vermiformes ou granulares e desenvolvem-se sobre cristais de albita.
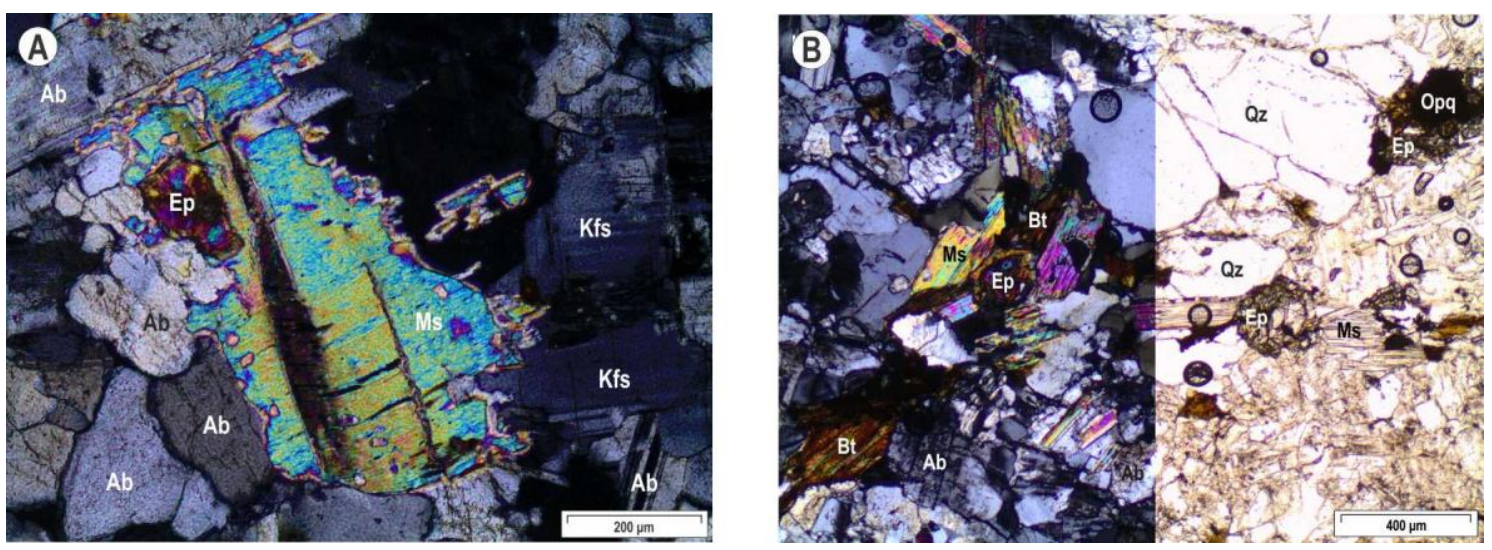

Figura 6: (A) Detalhe de cristal de muscovita dobrado em kink, incluindo parcialmente um cristal de epídoto. (B) Agregados irregulares de muscovita, biotita e epídoto. Muscovita (Ms), biotita (Bt), epídoto $(E p)$, albita $(A b)$, microclina $(K f s)$, quartzo $(Q z)$, minerais opacos $(O p q)$.

A apatita apresenta-se euédrica e com hábito acicular, fazendo contatos retos com os demais minerais da rocha (Figura 7A).

$\mathrm{O}$ zircão ocorre sob a forma euédrica e desenvolve contatos retos com os outros minerais. $\mathrm{Na}$ maior parte das vezes, ocorre em agregados dispostos em posições específicas da lâmina, inclusos, principalmente, por albita ou muscovita (Figura 7B).

A titanita apresenta-se desde anédrica a subédrica. Quando anédrica, exibe hábito granular e limita-se a ocorrer como produto de alteração nas bordas de minerais opacos (Figura 8). Quando subédrica, desenvolve contatos retos e reentrantes com os minerais adjacentes e comumente encontra-se associada a muscovita, sendo por ela inclusa parcial ou totalmente.

Os minerais opacos apresentam-se como cristais anédricos que, geralmente encontram-se associados a epídoto, clorita ou preenchendo planos de clivagem das micas. Os contatos com os demais minerais da lâmina são curvos e, ocasionalmente, retos. Por vezes, observa-se o desenvolvimento de titanita e epídoto nas bordas desses minerais. 

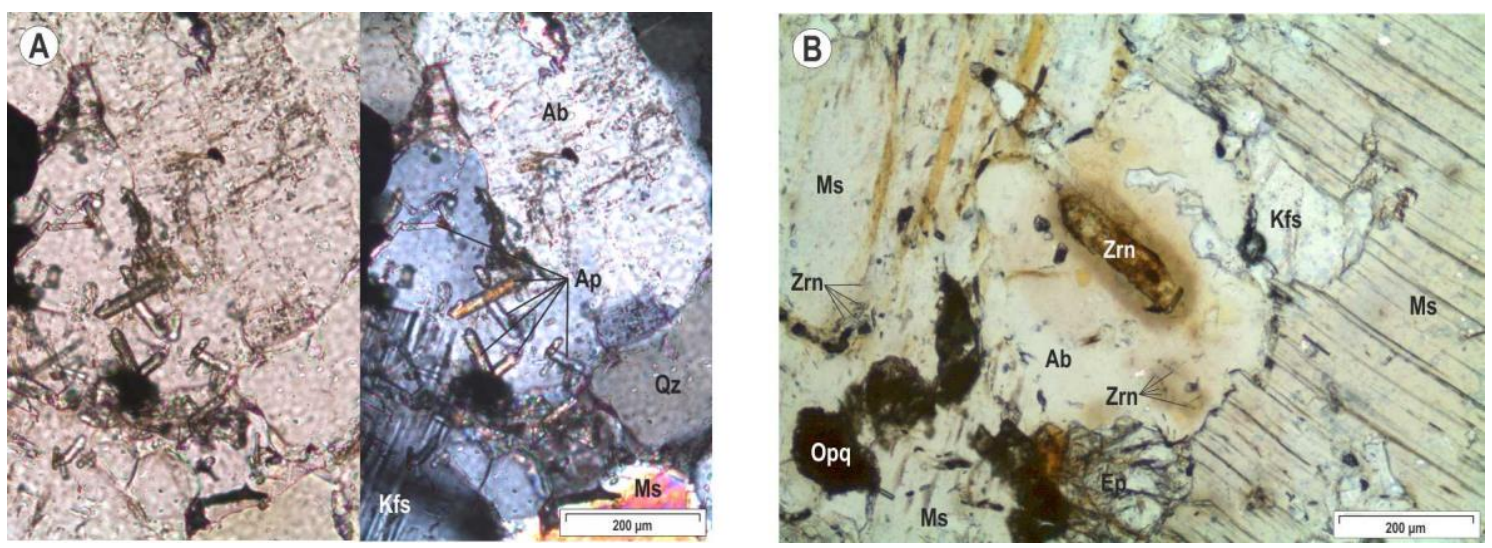

Figura 7: (A) Enxame de cristais idiomórficos de apatita com hábito acicular. (B) Detalhe de agregados de cristais de zircão inclusos em albita e muscovita, promovendo o desenvolvimento de halos pleocroicos. Apatita (Ap), albita (Ab), microclina (Kfs), muscovita (Ms), quartzo (Qz), zircão (Zrn), epídoto (Ep), minerias opacos (Opq).

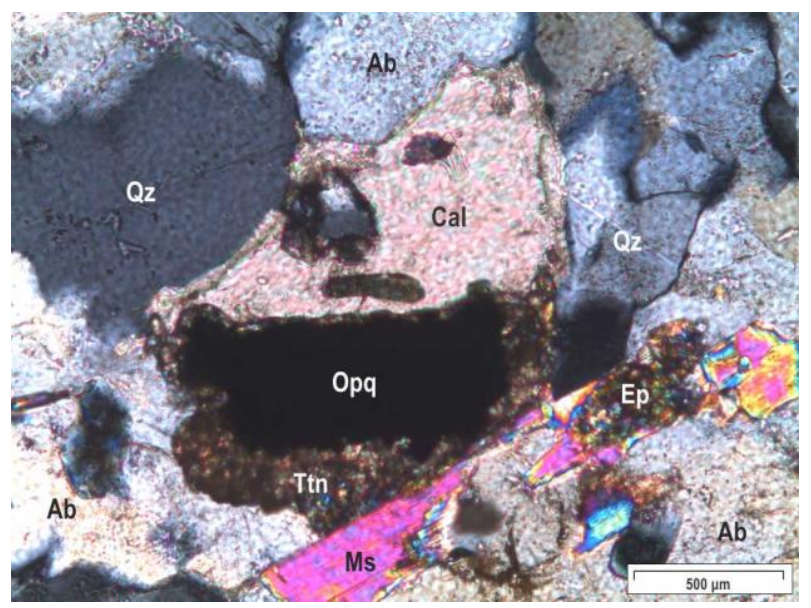

Figura 8: Cristal de mineral opaco sendo transformado para cristais de titanita granular, em contato irregular com calcita. Minerais opacos (Opq), titanita (Ttn), calcita (Cal), quartzo (Qz), albita (Ab), muscovita (Ms), epídoto (Ep).

O estudo das diferentes texturas, morfologia das fases minerais e suas relações de contato e inclusão permitiu estabelecer uma sequência de cristalização para os granitos do SLD (Figura 9).

Zircão, apatita e minerais opacos são os minerais acessórios de formação mais precoce, sendo seguidos pela cristalização do epídoto primário, euédrico a subédrico, que ocorre circundado por micas ou associado ao feldspato. O próximo mineral a se cristalizar corresponde a titanita magmática. Os cristais de titanita anédricos, que ocorrem envolvendo minerais opacos, são compreendidas como resultado da desestabilização destes. A biotita forma-se logo após a titanita magmática. Subsequente a cristalização da albita, se processou a cristalização do feldspato alcalino, que foi seguida pela formação da muscovita. O quartzo é o último mineral magmático a cristalizar.

A interação de fluidos magmáticos tardios com a assembleia mineral liquidus forma a clorita a partir da desestabilização da biotita; carbonato, epídoto secundário e sericita a partir da desestabilização dos cristais de albita e, subordinadamente, da microclina. Em condições iniciais do estágio subsolidus, o progressivo abaixamento da temperatura favorece a triclinização do ortoclásio, originando a microclina. 


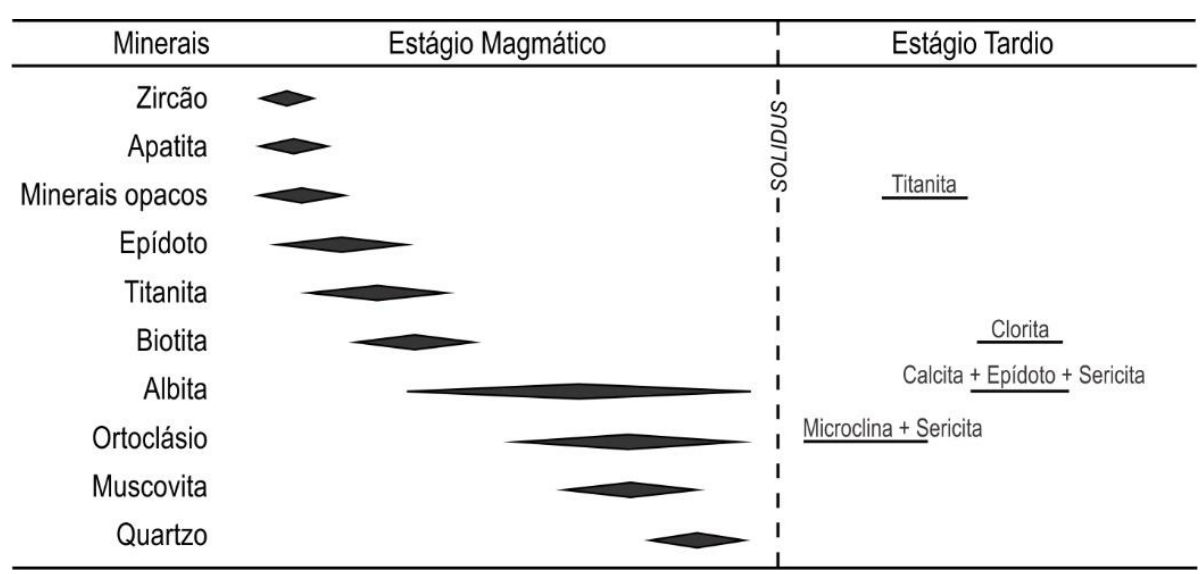

Figura 9: Sequência de cristalização definida com base nas relações texturais para os granitos do SLD.

\subsection{Geoquímica}

As análises geoquímicas de elementos maiores, assim como os dados normativos CIPW [18] correspondes as rochas estudadas são apresentados na Tabela 2.

Tabela 2: Análises geoquímicas de elementos maiores e composição normativa de rochas representativas do Stock Lagoa de Dentro. Muscovita Álcali-Feldspato Granito (MAFG), Muscovita Monzogranito $(M M G)$, Monzogranito $(M G)$.

\begin{tabular}{lrrrr}
\hline $\begin{array}{l}\text { Amostra } \\
\text { Fácies }\end{array}$ & $\begin{array}{c}\text { FDS-588 } \\
\text { MAFG }\end{array}$ & $\begin{array}{c}\text { FDS-589 } \\
\text { MMG }\end{array}$ & $\begin{array}{c}\text { FDS-590 } \\
\text { MAFG }\end{array}$ & $\begin{array}{c}\text { FDS-592 } \\
\text { MG }\end{array}$ \\
\hline $\mathrm{SiO}_{2}$ & 72,38 & 67,68 & 71,48 & 71,93 \\
$\mathrm{TiO}_{2}$ & 0,20 & 0,26 & 0,23 & 0,21 \\
$\mathrm{Al}_{2} \mathrm{O}_{3}$ & 14,81 & 18,66 & 15,08 & 14,83 \\
$\mathrm{Fe}_{2} \mathrm{O}_{3}$ & 1,35 & 1,21 & 1,42 & 1,34 \\
$\mathrm{MnO}$ & 0,01 & 0,01 & 0,01 & 0,01 \\
$\mathrm{MgO}$ & 0,20 & 0,44 & 0,28 & 0,25 \\
$\mathrm{CaO}$ & 0,54 & 0,55 & 0,69 & 0,85 \\
$\mathrm{Na} \mathrm{O}_{2} \mathrm{O}$ & 4,27 & 4,16 & 4,36 & 4,35 \\
$\mathrm{~K}_{2} \mathrm{O}$ & 5,00 & 5,72 & 5,12 & 4,99 \\
$\mathrm{P}_{2} \mathrm{O}_{5}$ & 0,08 & 0,04 & 0,07 & 0,06 \\
$\mathrm{LOI}$ & 1,00 & 1,02 & 1,10 & 1,00 \\
$\mathrm{Total}$ & 99,84 & 99,75 & 99,84 & 99,82 \\
$\mathrm{Na}_{2} \mathrm{O}+\mathrm{K}_{2} \mathrm{O}$ & 9,27 & 9,88 & 9,48 & 9,34 \\
$\mathrm{~K}_{2} \mathrm{O} / \mathrm{Na} \mathrm{O}_{2} \mathrm{O}$ & 1,17 & 1,37 & 1,17 & 1,14 \\
$\mathrm{~A} / \mathrm{CNK}$ & 1,10 & 1,32 & 1,07 & 1,07 \\
$\mathrm{Quartzo}$ & 27,18 & 19,87 & 24,83 & 25,51 \\
Plagioclásio & 38,29 & 37,67 & 39,86 & 40,63 \\
$(\%$ An) & $(5,3)$ & $(6,2)$ & $(7,0)$ & $(8,9)$ \\
Ortoclásio & 29,55 & 33,80 & 30,26 & 29,46 \\
$\mathrm{Coríndon}$ & 1,58 & 4,72 & 1,28 & 0,87 \\
$\mathrm{Hiperstênio}$ & 0,50 & 1,10 & 0,70 & 0,62 \\
$\mathrm{Rútilo}_{\text {Ilmenita }}$ & 0,19 & 0,25 & 0,22 & 0,20 \\
Hematita & 0,02 & 0,02 & 0,02 & 0,02 \\
Apatita & 1,35 & 1,21 & 1,42 & 1,34 \\
Total & 0,19 & 0,02 & 0,16 & 0,14 \\
\hline & 98,85 & 98,73 & 98,75 & 98,82 \\
\hline & & & &
\end{tabular}

Nos diagramas geoquímicos apresentados alocou-se, além dos dados obtidos nesse estudo, a área que delimita os dados de composições geoquímicas de 13 plútons leucograníticos do Domínio Macururé (MLDM), ocorrentes nos estados da Bahia e Sergipe [8, 9, 10, 11, 12]. 
Os dados geoquímicos de elementos maiores revelam composições ácidas para as rochas do SLD, com conteúdos de $\mathrm{SiO}_{2}$ variando entre 67,68 e 72,38\%. No diagrama Total Álcalis versus óxido de Sílício [19], é possível notar que todas as amostras alocam-se no campo dos granitos e ocupam a área das suítes alcalinas e subalcalinas (Figura 10). As relações entre $\mathrm{SiO}_{2}$ e $\mathrm{K}_{2} \mathrm{O}$ [20] assinalam a afinidade desses granitos com as rochas da série Cálcio-Alcalina de Alto Potássio (Figura 11). A amostra FDS-589, contudo, aloca-se nesses diagramas na área das suítes alcalinas e apresenta afinidade geoquímica com as suítes shoshoníticas.

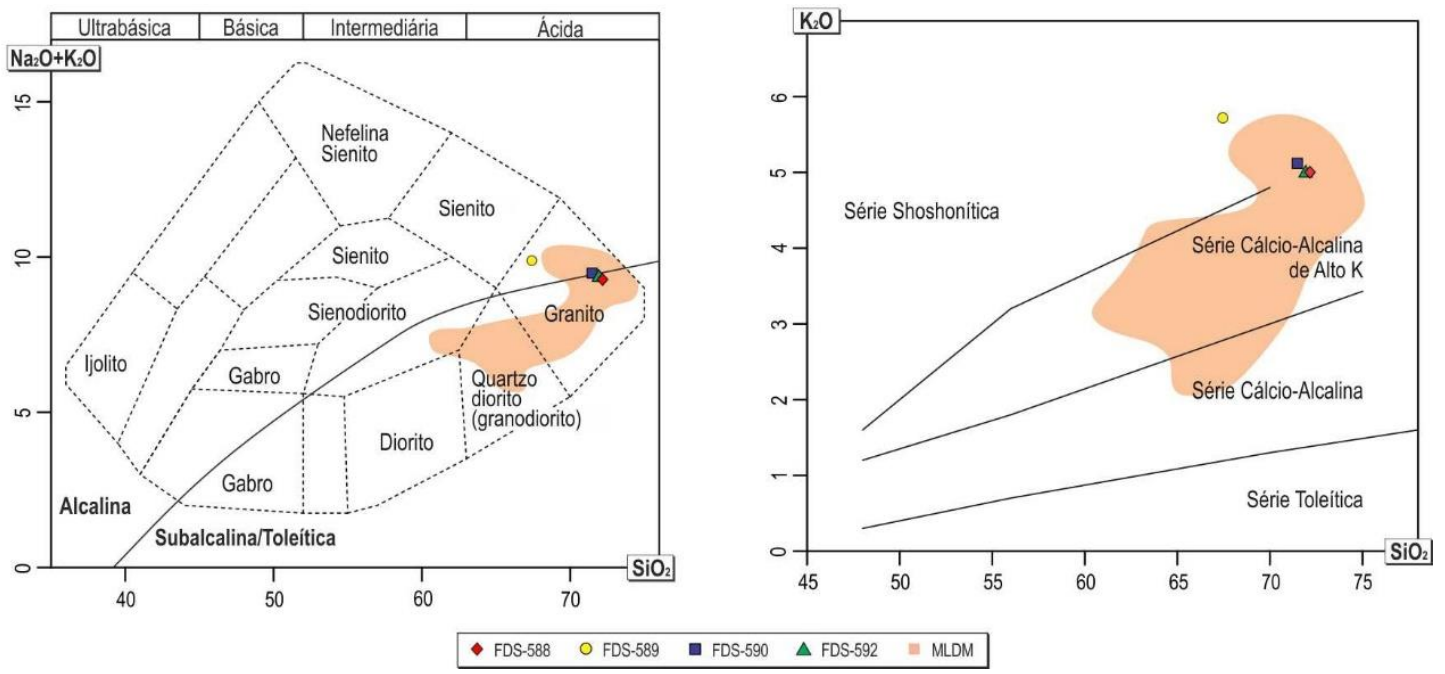

Figura 10: Diagrama Total Álcalis versus óxido de Silício [19] para classificação de rochas plutônicas, aplicado as rochas do SLD.

Figura 11: Diagrama $\mathrm{SiO}_{2}$ versus $\mathrm{K}_{2} \mathrm{O}$ [20] aplicado às rochas do SLD para identificação de afinidade com séries magmáticas.

O somatório de álcalis $\left(\mathrm{Na}_{2} \mathrm{O}+\mathrm{K}_{2} \mathrm{O}\right)$ nas rochas em estudo varia de 9,72 a $9,88 \%$, enquanto a razão $\mathrm{K}_{2} \mathrm{O} / \mathrm{Na}_{2} \mathrm{O}$ assume valores entre 1,14 e 1,37, caracterizando granitos potássicos [21] (Figura 12). Quanto à saturação em alumínio, as amostras estudadas são essencialmente peraluminosas e posicionam-se nos campos dos granitos Tipo I e Tipo S (Figura 13). A natureza peraluminosa dos granitos do SLD é corroborada pela presença de coríndon normativo observada em todas as amostras, que se traduz na mineralogia aluminosa modal representada, sobretudo, por muscovita e biotita. A amostra FDS-589 destaca-se do conjunto pelo maior conteúdo de $\mathrm{Al}_{2} \mathrm{O}_{3}$ e, consequentemente, maior razão molar $\mathrm{A} / \mathrm{CNK}$, resultando numa rocha fortemente peraluminosa.
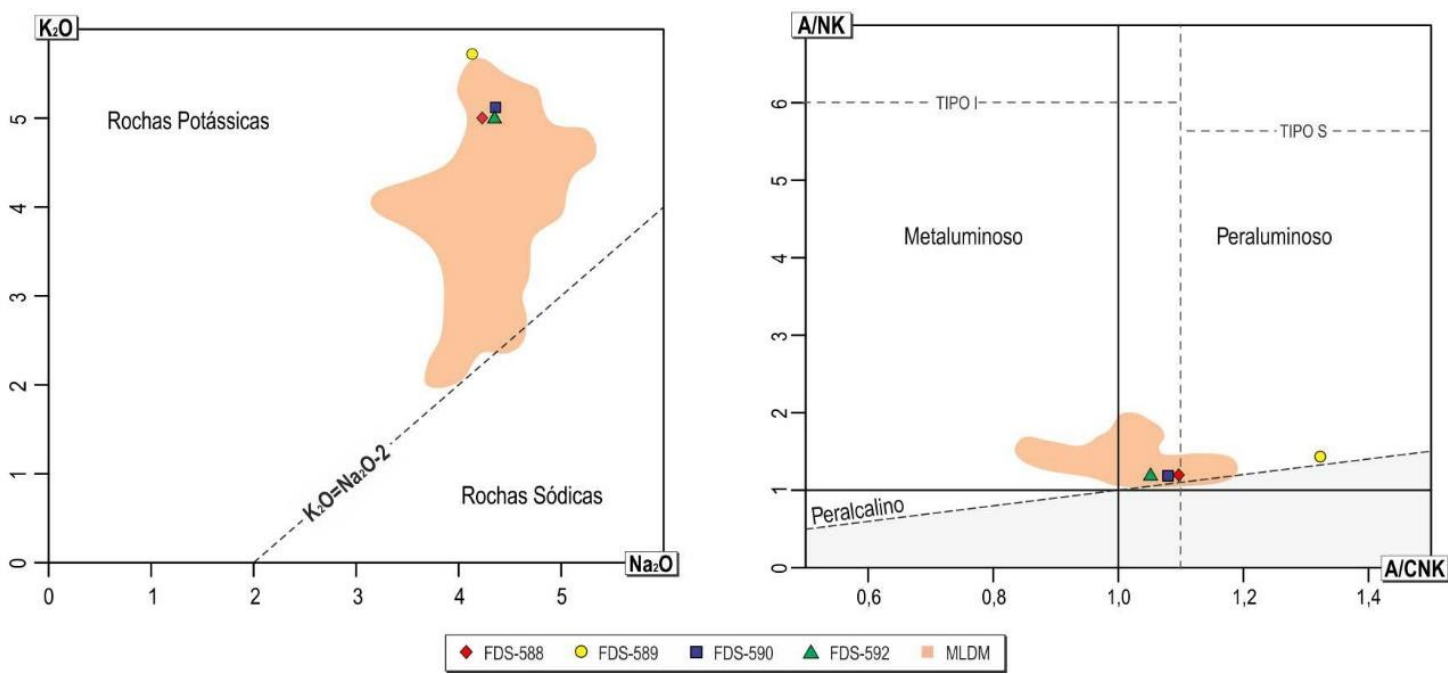

Figura 12: Diagrama $\mathrm{Na}_{2} \mathrm{O}$ versus $\mathrm{K}_{2} \mathrm{O}$ para classificação das rochas estudadas quanto ao conteúdo de potássio [21].
Figura 13: Diagrama A/CNK versus A/NK [22] aplicado aos granitos do SLD, com delimitação dos campos dos granitos tipos I e S [23]. 
As rochas do SLD são composicionalmente homogêneas em relação aos elementos traços, não exibindo diferenças significativas entre os tipos petrográficos (Tabela 3). Estes mostram-se relativamente enriquecidos em $\mathrm{Ba}(859-1157 \mathrm{ppm})$ e com pequenas variações nos conteúdos de $\mathrm{Rb}(216,0-226,4 \mathrm{ppm})$ e $\mathrm{Sr}(287,0-312,4 \mathrm{ppm})$. Também são verificados baixos valores de $\mathrm{Nb}$ (2,0-2,2 ppm), Y (1,9-4,5 ppm), Ta (0,1-0,3 ppm) e Zr (139,0-161,2 ppm).

Tabela 3: Análises geoquímicas de elementos traços de rochas representativas do Stock Lagoa de Dentro. Muscovita Álcali-Feldspato Granito (MAFG), Muscovita Monzogranito (MMG), Monzogranito $(M G)$.

\begin{tabular}{|c|c|c|c|}
\hline $\begin{array}{l}\text { Amostra } \\
\text { Fácies }\end{array}$ & $\begin{array}{c}\text { FDS-588 } \\
\text { MAFG }\end{array}$ & $\begin{array}{c}\text { FDS-590 } \\
\text { MAFG }\end{array}$ & $\begin{array}{c}\text { FDS-592 } \\
\text { MG }\end{array}$ \\
\hline $\mathrm{Ba}$ & 903 & 1157 & 859 \\
\hline $\mathrm{Rb}$ & 226,8 & 216,0 & 223,4 \\
\hline $\mathrm{Th}$ & 32,8 & 34,3 & 28,8 \\
\hline $\mathrm{Nb}$ & 2,0 & 2,2 & 2,1 \\
\hline $\mathrm{Ta}$ & 0,3 & 0,1 & 0,2 \\
\hline $\mathrm{Sr}$ & 279,8 & 312,4 & 287,0 \\
\hline $\mathrm{Zr}$ & 139,0 & 161,2 & 144,9 \\
\hline $\mathrm{Hf}$ & 4,4 & 4,3 & 4,1 \\
\hline $\mathrm{Y}$ & 2,1 & 4,5 & 1,9 \\
\hline $\mathrm{La}$ & 27,6 & 61,2 & 40,7 \\
\hline $\mathrm{Ce}$ & 64,6 & 110,4 & 76,2 \\
\hline $\operatorname{Pr}$ & 5,52 & 10,54 & 7,37 \\
\hline $\mathrm{Nd}$ & 17,5 & 35,1 & 25,2 \\
\hline $\mathrm{Sm}$ & 2,84 & 4,44 & 3,66 \\
\hline $\mathrm{Eu}$ & 0,62 & 0,90 & 0,72 \\
\hline $\mathrm{Gd}$ & 1,73 & 2,71 & 1,91 \\
\hline $\mathrm{Tb}$ & 0,16 & 0,22 & 0,16 \\
\hline Dy & 0,60 & 0,85 & 0,48 \\
\hline Ho & 0,07 & 0,10 & 0,05 \\
\hline Er & 0,19 & 0,31 & 0,14 \\
\hline $\mathrm{Tm}$ & 0,02 & 0,04 & 0,02 \\
\hline $\mathrm{Yb}$ & 0,16 & 0,21 & 0,12 \\
\hline $\mathrm{Lu}$ & 0,01 & 0,03 & 0,01 \\
\hline$\sum$ ETR & 121,62 & 227,05 & 156,74 \\
\hline $\mathrm{La}_{\mathrm{N}} / \mathrm{Yb}_{\mathrm{N}} *$ & 115,34 & 194,87 & 226,79 \\
\hline $\mathrm{Eu} / \mathrm{Eu}^{*}$ & 0,79 & 0,73 & 0,74 \\
\hline
\end{tabular}

O diagrama com os espectros de ETR normalizados pelo condrito de Nakamura (1974) [24] mostram padrões similares para as rochas em estudo (Figura 14), indicando cogeneticidade. De maneira geral, observa-se um acentuado enriquecimento dos ETR leves em relação aos ETR pesados $\left(115<\mathrm{La}_{N} / \mathrm{Yb}_{\mathrm{N}}<226\right)$. Nas amostras do SLD também são verificadas moderadas anomalias negativas de Eu $(0,73$ a 0,79$)$, sugerindo a participação do plagioclásio durante a evolução dos magmas que originaram essas rochas.

No diagrama multielementar normalizado pelos valores do condrito de Thompson (1982) [25], o conjunto das amostras estudadas tem comportamento semelhante e caracterizado pelo enriquecimento dos LILE e ETR leves em relação aos HFSE e ETR pesados (Figura 15). Pronunciados vales são observados em Ta, $\mathrm{Nb}$, Ti e P, assim como discretas anomalias negativas de Sr. As depleções em Ta, $\mathrm{Nb}$ e Ti são presentes em todas as amostras e este comportamento é usualmente interpretado na literatura como assinatura de magmas orogênicos, devido a retenção desses elementos pelo rútilo ou ilmenita durante a fusão parcial do manto em condições oxidantes [26]. Por outro lado, anomalias negativas de P e Sr podem ser explicadas em magmas riolíticos como resposta ao fracionamento precoce de apatita e do plagioclásio, respectivamente. 


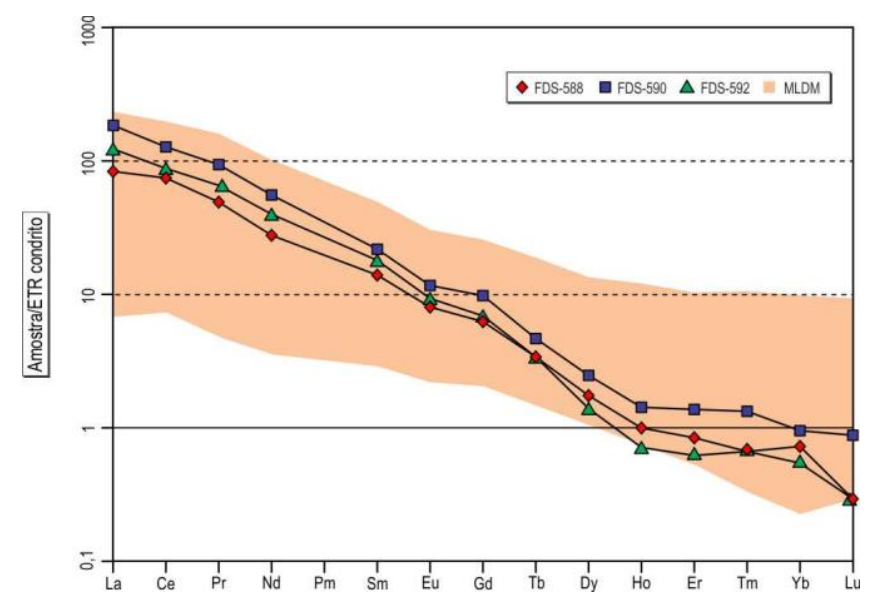

Figura 14: Diagrama com espectros de ETR para as rochas do Stock Lagoa de Dentro, normalizadas pelo condrito de Nakamura (1974) [24].

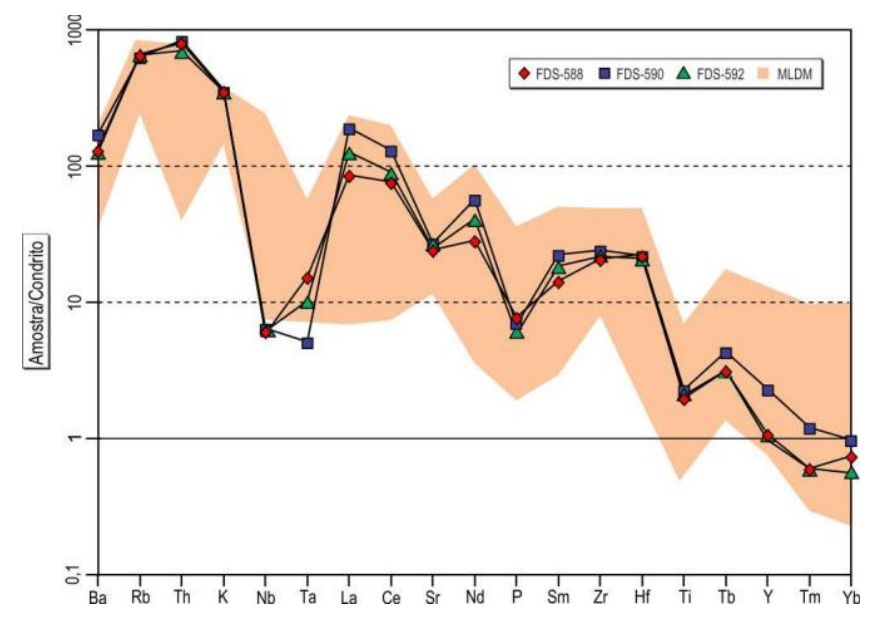

Figura 15: Diagrama multielementar para as rochas do Stock Lagoa de Dentro, normalizadas pelo condrito de Thompson (1982) [23].

A distribuição das amostras analisadas no diagrama discriminante de ambiência tectônica $Y$ versus $\mathrm{Nb}$ [27] sugere um magmatismo compatível com o de granitos gerados em ambientes de arco vulcânico, em estágio sincrônico ao evento colisional (Figura 16).

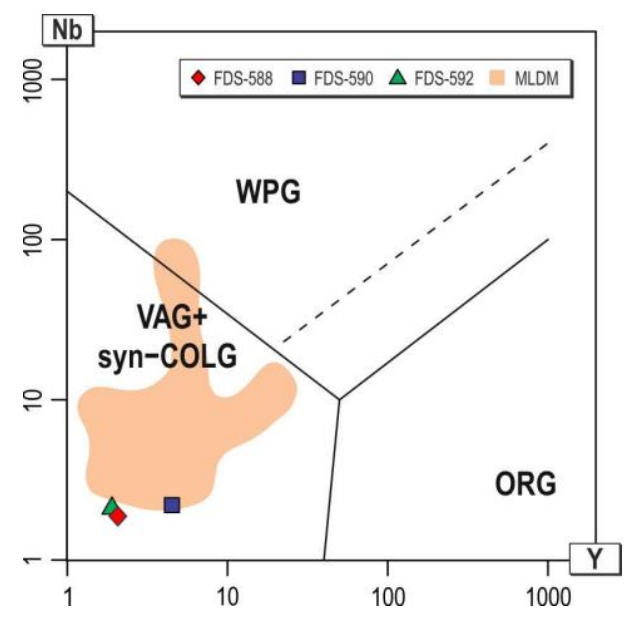

Figura 16: Diagrama Y versus Nb de Pearce et al. (1984) [27] para discriminação de ambiência tectônica aplicado às rochas estudadas. 


\section{CONCLUSÃO}

As rochas do Stock Lagoa de Dentro apresentam grande homogeneidade composicional e textural, sendo constituído por granitos de coloração rósea a cinzenta, com textura fanerítica equigranular e granulação média. Esses granitos são isotrópicos, contudo, localmente exibem leve anisotropismo, definido pela orientação magmática dos cristais de micas, concordantemente com a foliação regional. Como encaixantes do SLD são observados os metassedimentos do Domínio Macururé. Estes consistem em filitos e metarenitos, que geralmente são ricos em minerais micáceos e preservam suas estruturas primárias.

A petrografia possibilitou a identificação de três tipos petrográficos no stock estudado: Muscovita Álcali-Feldspato Granito, Muscovita Monzogranito e Monzogranito. Essas rochas apresentam mineralogia monótona, composta essencialmente por quartzo, albita, microclina e muscovita. A biotita ocorre como principal mineral máfico, enquanto que, epídoto, zircão, apatita, ilmenita e titanita são fases acessórias usuais. Os minerais formados quando da desestabilização da assembleia primária correspondem a calcita, sericita, clorita, epídoto e titanita.

A caracterização geoquímica do SLD mostrou-se coerente com os resultados obtidos para outros corpos leucograníticos do Domínio Macururé. Os granitos do SLD são peraluminosos, potássicos e exibem afinidades com as suítes Cálcio-Alcalina de Alto Potássio e Shoshonítica. Os conteúdos de coríndon normativo corroboram o caráter peraluminoso das rochas estudadas e ratificam a ocorrência modal de minerais aluminosos, como muscovita e biotita. Nos diagramas ETR e multielementar observa-se um enriquecimento de ETR leves e LILE em relação aos ETR pesados e HFSE. Também são verificadas discretas anomalias negativas de $\mathrm{Eu} \mathrm{e} \mathrm{Sr}$, correlacionáveis ao fracionamento do plagioclásio. Semelhantemente, a depressão de $\mathrm{P}$ é condizente com a cristalização da apatita. Pronunciadas anomalias negativas de $\mathrm{Ta}, \mathrm{Nb}$ e $\mathrm{Ti}$ assinalam o caráter orogênico dos magmas que originam as rochas do SLD. Nos diagramas de ambiência tectônica, as amostras posicionam-se no campo dos granitos sin-colisionais, com assinatura de rochas de arco vulcânico.

\section{AGRADECIMENTOS}

Este trabalho foi desenvolvido junto ao Laboratório de Petrologia Aplicada à Pesquisa Mineral da Universidade Federal de Sergipe (LAPA-UFS) e apresenta parte dos resultados do trabalho de conclusão de curso do primeiro autor. Os autores externam seus agradecimentos ao Conselho Nacional de Desenvolvimento Científico e Tecnológico (CNPq) pelas bolsas de iniciação científica obtidas durante a graduação e pelo suporte financeiro desta pesquisa (Processos: 473013/2013-4 e 308059/2014-0). Os autores agradecem também à Secretaria de Planejamento, Orçamento e Gestão do Governo de Sergipe (SEPLAG) pela concessão das fotografias aéreas utilizadas na confecção do mapa fotogeológico e a Superintendência de Salvador do Serviço Geológico do Brasil (CPRM) pelo apoio na confecção das lâminas delgadas.

\section{REFERÊNCIAS BIBLIOGRÁFICAS}

1. Conceição JA, Rosa MLS, Conceição H. Sienogranitos leucocráticos do Domínio Macururé, Sistema Orogênico Sergipano, Nordeste do Brasil: Stock Glória Sul. Brazilian Journal of Geology. 2016 Mar; 46(1):63-77, doi: 10.1590/2317-4889201620150044.

2. Humphrey L, Allard GO. O Geossinclinal de Propriá - província tectônica do pré-cambriano posterior, recém descoberta no escudo brasileiro. Boletim Técnico da Petrobrás. 1967:409-430.

3. Silva Filho M, Bomfim LFC, Santos RA, Leal RA, Santana AC, Filho PAB. Geologia da Geossinclinal Sergipana e do seu embasamento Alagoas, Sergipe e Bahia: Projeto Baixo São Francisco/Vaza Barris. Brasília: DNPM/CPRM; 1979. 134 p.

4. Brito Neves BB. Regionalização geotectônica do precambiano nordestino [thesis]. São Paulo: Universidade de São Paulo; 1975. 207 p.

5. Davison I, Santos RA. Tectonic Evolution of the Sergipano Fold Belt, NE Brasil, during Brasiliano Orogeny. Precambrian Research. 1989; 45:319-342. 
6. D'el-Rey Silva LJH. Tectonic evolution of the Sergipano Belt, NE Brazil. Revista Brasileira de Geociências. 1995 Dec; 25(4):315-332.

7. D'el-Rey Silva LJH. Basin infilling in the southern-central part of the Sergipano Belt (NE Brazil) and implications for the evolution of Pan-African/Brasiliano cratons and Neoproterozoic sedimentary cover. Journal of South American Earth Sciences. 1999; 12:453-470.

8. Conceição JA. Petrologia do Stock Granítico Glória Sul, Faixa Sergipana, setor sul da Província Borborema, Sergipe [dissertation]. São Cristóvão: Universidade Federal de Sergipe; 2014. 145 p.

9. Oliveira ACS. Petrogênese do Stock Granítico Monte Alegre, nordeste do Domínio Macururé, Faixa Sergipana [dissertation]. São Cristóvão: Universidade Federal de Sergipe; 2014. 130 p.

10. Lisboa VAC. Petrologia e Geocronologia do Maciço Glória Norte, Faixa de Dobramentos Sergipana, NE do Brasil [dissertation]. São Cristóvão: Universidade Federal de Sergipe; 2014. 140 p.

11. Mendonça, LH. Geologia, Petrografia e Geoquímica de Stocks Graníticos no município de Canhoba, Sergipe [monograph]. São Cristóvão: Universidade Federal de Sergipe; 2013. 182 p.

12. Oliveira EP, Bueno JF, McNaughton NJ, Silva Filho AF, Nascimento RS, Donatti-Filho JP. Age, composition, and source of continental arc- and syn-collision granites of the Neoproterozoic Sergipano Belt, Southern Borborema Province, Brazil. Journal of South American Earth Sciences. 2014; 58:257280, doi: 10.1016/j.jsames.2014.08.003.

13. Souza JD, Santos RA. Mapa Geológico do Estado de Sergipe. Salvador: CODISE/CPRM; 1997.

14. Le Maitre RW, Streckseisen A, Zanettin B, Le Bas MJ, Bonin B, Bateman P, et al. Igneous Rocks - A classification and glossary of terms. Recommendations of the International Union of Geological Sciences - Subcommission on the Systematics of Igneous Rocks. New York: Cambridge University Press; 2002. 254 p.

15. Janoušek V, Farrow CM, Erban V. Interpretation of Whole-rock Geochemical Data in Igneous Geochemistry: Introducing Geochemical Data Toolkit (GCDKit). Journal of Petrology. 2006 Jun; 47(6):1255-1259, doi: 10.1093/petrology/egl013.

16. Streckeisen AL. To each plutonic rocks its proper name. Earth Science Reviews. 1976:1-33.

17. Lameyre J, Bowden P. Plutonic rocks types series: Discriminations of various granitoid series and related rocks. Journal of Vulcanology and Geothermal Research. 1982; 14:169-186.

18. Cross W, Iddings JP, Pirsson LV, Washington HS. Quantitative classification of igneous rocks: University of Chicago Press; 1903. 188 p.

19. Cox KG, Bell JD, Panknurst RJ. The interpretation of igneous rocks. 1st ed.: George Allen \& Unwin; 1979. $459 \mathrm{p}$.

20. Peccerillo A, Taylor SR. Geochemistry of Eocene Calc-Alkaline Volcanic Rocks form the Kastamonu Area, Northen Turkey. Contribution to Mineralogy and Petrology. 1976; 58:63-81.

21. Le Maitre RW, Bateman P, Dudek A, Keller J, Lameyre J, Le Bas MJ, et al. A classification of igneous rocks and glossary of terms: recommendation of the International Union of Geological Sciences Subcomission on the Systemtics of Igneous Rocks London: Blackwell Scientific Publications; 1989. $193 \mathrm{p}$.

22. Maniar PD, Piccoli PM. Tectonic discrimination of granitoids. Geological Society of American Bulletin. 1989; 101:635-643.

23. Chappell BW, White JR. I- and S- type granites in the Lachlan Fold Belt. Earth Sciences. 1992; 83:126.

24. Nakamura N. Determination of REE, Ba, Fe, $\mathrm{Mg}, \mathrm{Na}$ and $\mathrm{K}$ in carbonaceous and ordinary chondrites. Geochemica et Cosmochimica Acta. 1974; 38:757-775.

25. Thompson RN. Magmatism of the Britsh Tertiary volcanic Province. Scottish Journal of Geology. 1982; 18:50-107.

26. Ringwood AE. Slab-mantle interation: petrogenesis of interplate magmas and structure of the upper mantle. Chemical Geology. 1990; 82:187-207.

27. Pearce JA, Harris NBW, Tindle AG. Trace Elements Discrimination Diagrams for the Tectonic Interpretation of Granitic Rocks. Journal of Petrology. 1984; 25:956-983. 